\title{
Utilization of LABAs versus SABAs in Albanian Insured Outpatients with COPD during 2008-2012
}

\author{
Alida Sina \\ PhD Student, Health Insurance Institute, Tirana, Albania \\ E-mail: alida_sina@yahoo.com
}

Zamira Shabani

University of Shkoder "Luigj Gurakuqi”, Sheshi "2 Prilli”, Shkodër - Albania E-mail: shabanizamira@yahoo.com

\section{Doi:10.5901/mjss.2013.v4n9p573}

\section{Abstract}

\begin{abstract}
Introduction: Inhaled $\beta 2$-agonists as bronchodilators are commonly used in Chronic Obstructive Pulmonary Disease (COPD). These drugs can be either short-acting (SABA) or long-acting ( $L A B A)$. The aim of this retrospective study is to evaluate the use patterns of inhaled LABAs versus inhaled SABAs reimbursed in Albania during 2008-2012 for ambulatory COPD treatment. Methods: Data on analyzed drugs for COPD treatment were taken from Health Insurance Institute database. ATC/DDD methodology was used to quantify the consumption of inhaled $\beta 2$-agonists in DDD/1000 inhabitants/day and the results were expressed as percentage of annual drug use. All the data are calculated with Microsoft Office Excel program. Results: The utilization ratio of LABAs to SABAs was: 4:96 in 2008, 9.5:90.5 in 2009, 25:75 in 2010, 34:66 in 2011 and $45: 55$ in 2012 respectively. During 2009-2012 the use of LABAs was increased, especially when they were in combination with inhaled corticosteroids (ICS). These combinations represented $5 \%, 18 \%, 24 \%$ and $23 \%$ of total annual consumption during four years respectively. In 2012 Salmeterol plus Fluticasone was the most used combination and Indicaterol was the most used among plain LABAs. Conclusion: The use of inhaled LABAs continually is increased versus SABAs ones for COPD treatment in Albanian insured outpatients during 2008-2012. These changes refered to the international guidelines wich recommend SABAs for as-needed symptom relief and LABAs as long-term maintenance therapies. In addition LABA/ICS combinations have greater efficacy than either of its components used alone.
\end{abstract}

Keywords: bronchodilators, chronic, disease, obstructive, pulmonary.

\section{Introduction}

Chronic Obstructive Pulmonary Disease (COPD) is a major cause of chronic morbidity and mortality throughout the world. COPD is characterized by persistent airflow limitation that is not fully reversible. The airflow limitation is usually progressive and associated with an enhanced chronic inflammatory response in the airways and the lung to noxious particles or gases. ${ }^{1}$ COPD encompasses a progressive group of disorders (i.e., emphysema and chronic bronchitis) that cause airflow obstruction and breathing problems. ${ }^{2}$

Bronchodilator medications are central to symptom management in COPD. Based on efficacy and side effects, inhaled bronchodilators are preferred over oral ones. ${ }^{1}$ As a result, inhaled $\beta_{2}$-agonists being bronchodilatory drugs are commonly used for the treatment of this condition. There are several inhaled $\beta_{2}$-agonists available. According to the duration of bronchodilator effect, they may be either short-acting $\beta_{2}$-agonists (SABAs) or long-acting $\beta_{2}$-agonists (LABAs).

In Albania the number of reimbursed drugs is increased over years with different medications belong to inhaled $\beta_{2}$ agonists. The combinations of LABAs and inhaled corticosteroids (ICS), salmeterol plus fluticasone and budesonide plus formoterol respectively, have been reimbursed for the first time in 2009. Then the inhaled ultra-LABA, indicaterol, with a 24-hour duration of bronchodilation has been added in the reimbursed drug list in 2011.

Inhaled and reimbursed $\beta_{2}$-agonists should be prescribed in every case based on the specific protocols. These protocols serve as national guidelines in day-to-day medical practice in primary care and are prepared in accordance with current international and professional guidelines for appropriate drug use in COPD. Having in consideration the changes of reimbused drug list and also the recommendations of national and international guidelines, the aim of this 
retrospective study is to evaluate the use patterns of inhaled LABAs versus inhaled SABAs reimbursed in Albania during 2008-2012 for ambulatory COPD treatment.

\section{Materials and Methods}

Electronic data on drugs reimbursed for Albanian outpatients with COPD during the years 2008-2012 were taken retrospectively from the Albanian Health Insurance Institute database. For this purpose it was used International Classification of Diseases, Ninth Revision (ICD-9) and also International Anatomical Therapeutic Chemical (ATC) classification system of drugs.

Reimbursed drugs used for the treatment of outpatients who had a diagnosis of COPD ( ICD-9 codes: 491 (chronic bronchitis), 492 (emphysema) and/or 496 (chronic obstructive pulmonary disease, not elsewhere classified), were primarily obtained from database.

Then $\beta 2$-agonists were selected from all those drugs applying the ATC classification system. This classification divides the drugs in groups at five different levels according to the organ or system on which they act and according to their chemical, pharmacological and therapeutic properties.3,4

At the second ATC level, $\beta 2$-agonists belonged to R03 therapeutic group-drugs for obstructive airway diseases. Inhaled $\beta 2$-agonists were selected from this group, using the codes of lower levels until the fifth level of chemical substance.

ATC/DDD methodology, developed by the World Health Organization, was used to quantify the consumption of inhaled $\beta 2$-agonists in DDD/1000 inhabitants/day and the results were expressed as percentage of annual drug use. It was used Microsoft Office Excel Program for all the calculations. The number of COPD outpatients who had taken at least a reimbursed medical prescription over a year had been used as the denominator.

The Defined Daily Dose (DDD) provides a fixed unit of measurement independent of price, currencies, package size and strength enabling the researcher to assess trends in drug consumption.4

The DDDs of plain inhaled products that were objects of this study were taken from the ATC/DDD Index-2012. Plain products are defined as preparations containing one active component (including stereoisomeric mixtures). 4 Products containing two or more active ingredients are regarded as combination products. The DDDs assigned for combination products are based on the main principle of counting the combination as one daily dose, regardless of the number of active ingredients included in the combination.4 For combined products, the DDDs were taken from List of DDDs for combined products which is available on the website www.whocc.no

\section{Results}

The total consumption of inhaled $\beta_{2}$-agonists reimbursed for the treatment of COPD in primary care in Albania was increased during 2008-2012. Although short- and long-acting inhaled $\beta_{2}$-agonists showed the increasing trends of consumption, the rhythm of such increases was different (Figure 1). As a result, their propotions versus the annual consumption of inhaled $\beta_{2}$-agonists reimbursed for COPD had changed a lot over five years (Figure 2).

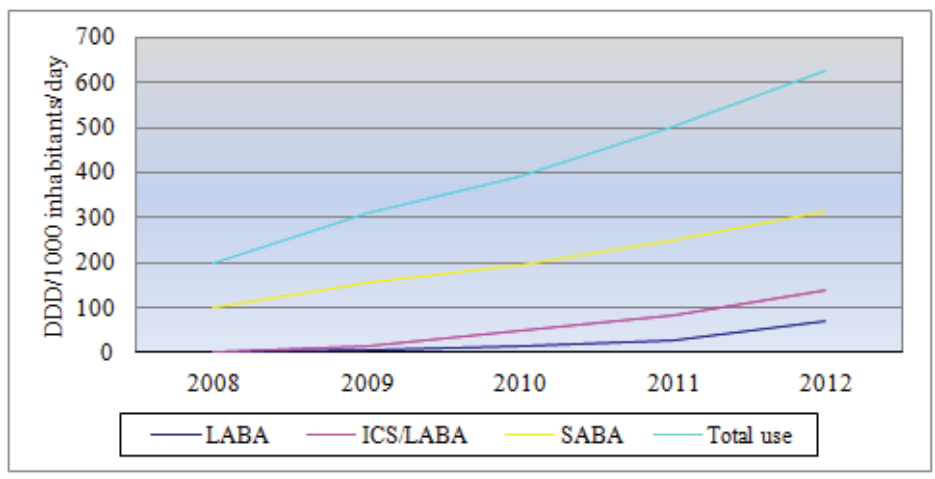

Figure 1. Utilization of inhaled and reimbursed $\beta_{2}$-agonists in COPD in Albania 
The consumption of long-acting inhaled $\beta_{2}$-agonists (LABAs) represented $4 \%, 9.5 \%, 25 \%, 34 \%$ and $45 \%$ respectively of annual consumption of inhaled $\beta_{2}$-agonists used for the treatment of COPD in insured outpatients in Albania during 20082012. On the other hand the consumption of short-acting inhaled $\beta_{2}$-agonist (SABAs) represented $96 \%, 90.5 \%, 75 \%$, $66 \%$ and $55 \%$ respectively of the annual consumption of inhaled $\beta_{2}$-agonists, used during the same time period and in the same outpatients with COPD (Figure 2).

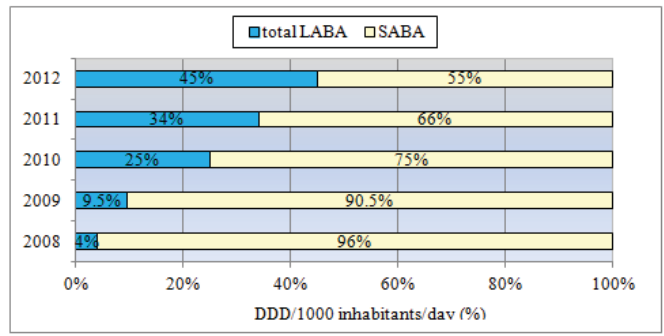

Figure 2. Utilization of LABAs versus SABAs in Albanian insured outpatients with COPD

In the pharmacotherapeutical group of LABAs the consumption of their combinations with inhaled corticosteroids (ICS) represented $5.2 \%, 18 \%, 24 \%$ and $23 \%$ of annual use of inhaled $\beta_{2}$-agonsits reimbursed for COPD treatment in primary care.

The increase of consumption of inhaled ICS/LABA combinations comparing to the use of plain LABAs was more evident from 2009 to 2011. In 2012 the consumptions of LABAs, as plain and combined preparations, were almost equivalent (Figure 3).

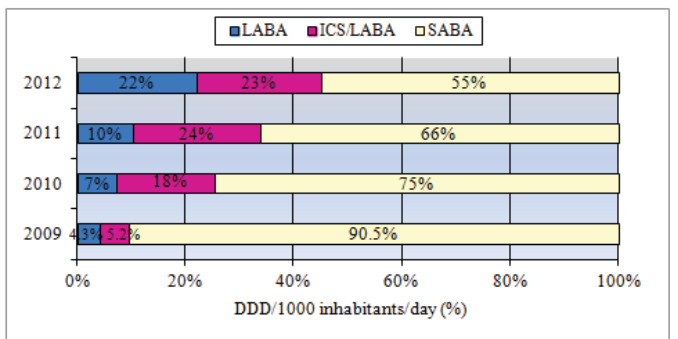

Figure 3. Utilization of ICS/LABA combinations vs single LABAs in Albanian insured outpatients with COPD

Formoterol, salmeterol and indicaterol were three single LABAs reimbursed in Albania for ambulatory COPD treatment. Indicaterol was recently added to the reimbursed drug list, whereas two other drugs had been previously reimbursed. Among these drugs, formoterol had the greatest consumption from 2009 to 2011. In the meantime salmeterol showed a continual decrease in consumption. This inhaled drug represented only $0.4 \%$ of annual inhaled $\beta_{2}$-agonists consumption reimbursed for COPD in 2012. The use of indicaterol was significantly bigger than the consumption of formoterol in 2012. Its consumption represented $13.5 \%$ of annual inhaled $\beta_{2}$-agonists use reimbursed for COPD in primary care, whereas formoterol showed $8.1 \%$ of this annual consumption. (Figure 4).

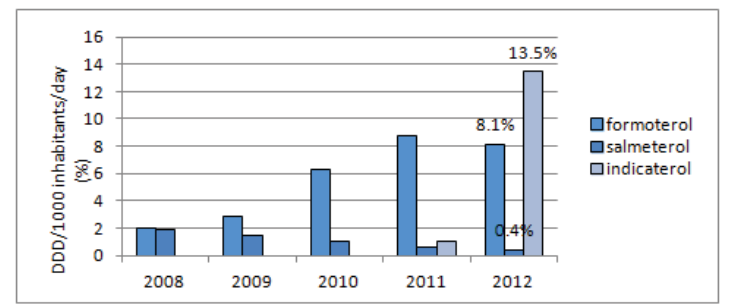

Figure 4. Utilization of plain LABAs as active substances reimbursed for ambulatory COPD treatment in Albania 
Among inhaled ICS/LABA combinations, salmeterol plus fluticasone was more used than budesonide plus formoterol in two last years. The difference in consumption of these two inhaled combinations was more evident in 2012 when the ratio of their utilizations was $14.5: 8.5$.

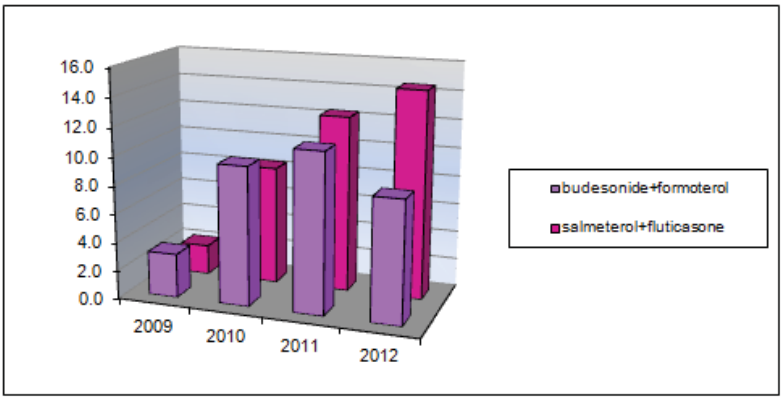

Figure 5-Utilization of ICS/LABA combinations reimbursed for ambulatory COPD treatment in Albania

\section{Discussion}

As COPD is a progressive disease, guidelines including those of Global Initiative for Chronic Obstructive Lung Disease $(G O L D)^{1}$, the American Thoracic Society/European Respiratory Society (ATS/ERS) ${ }^{5}$ and the National Institute for Health and Clinical Excellence ${ }^{6}$ recommend an escalation of drug therapy with increasing severity of COPD, starting with shortacting inhaled bronchodilators used on as-needed basis, proceeding to scheduled administration of long-acting inhaled bronchodilators, and finally advancing to inhaled corticosteroids in patients with severe or very severe disease with frequent exacerbations. (Table 1). However, based on recent findings of the TORCH study that salmeterol plus fluticasone is associated with a reduced rate of exacerbations, improved lung function and health-related quality of life, and possible survival benefits, European regulatos recently approved its use in patients with milder COPD (FEV $1 \leq 60 \%$ of predicted pre-bronchodilator value and history of exacerbations). ${ }^{7}$

Table 1: Recommended Therapy at Each Stage of COPD 1

\begin{tabular}{|c|c|c|c|c|c|}
\hline $\begin{array}{c}\text { COPD } \\
\text { Stage }\end{array}$ & FEV1 & $\begin{array}{c}\text { Influenza } \\
\text { Vaccination } \\
\text { I- Mild }\end{array}$ & $\begin{array}{c}\text { FEV1 } 280 \% \text { of predicted } \\
\text { Bronchodilators }\end{array}$ & $\begin{array}{c}\text { Long-acting } \\
\text { Bronchodilators }\end{array}$ & $\begin{array}{c}\text { Inhaled } \\
\text { Glucocorticosteroids }\end{array}$ \\
\hline $\begin{array}{c}\text { II - } \\
\text { Moderate }\end{array}$ & $50 \% \leq F E V 1<80 \%$ of predicted & $\sqrt{ }$ & $\sqrt{ }$ & $\sqrt{ }$ & \\
\hline $\begin{array}{c}\text { III - } \\
\text { Severe }\end{array}$ & $30 \% \leq F E V 1<50 \%$ of predicted & $\sqrt{ }$ & $\sqrt{ }$ & $\sqrt{ }$ \\
\hline $\begin{array}{c}\text { IV - Very } \\
\text { Severe }\end{array}$ & $\begin{array}{c}\text { FEV1<30\% of predicted or } \\
\text { FEV1<50\% of predicted plus } \\
\text { chronic respiratory failure }\end{array}$ & $\sqrt{ }$ & $\sqrt{ }$ & $\sqrt{ }$ & \\
\hline
\end{tabular}

$\mathrm{FEV}_{1}$, forced expiratory volume in 1 second

Short-acting inhaled bronchodilators have a rapid onset of action and are recommended as rescue medication for all severities of COPD to relieve acute symptoms of bronchospasm..$^{8}$ On the other hand their bronchodilatory effect lasts for 4-6 hours, so they are not convenient for the maintained therapy. Salbutamol, the "gold standart" fast-acting rescue medication, ${ }^{9}$ which takes effect within a few minutes (1 to 5 minutes) from dosing is the alone SABA reimbursed in Albania. Its consumption, as percentage of annual inhaled $\beta_{2}$-agonists use, has decreased from 2008 to 2012, because this drug provides only short-term relief from COPD symptoms (Figure 2).

The total use of reimbursed LABAs in treating COPD outpatients is gradually increased during five years. LABAs are recommended as first-line agents for maintenance therapy in patients with moderate to very severe disease and those with daily symptoms, based on the prolonged duration of action of 12 or more hours. These bronchodilators have been shown to improve symptoms, health-related quality of life and lung function, and reduce exacerbations and hospitalisations. ${ }^{10,11}$ 
Formoterol, salmeterol and indicaterol reimbursed as plain LABA preparations represent different utilizations in COPD. Formoterol is more preferred than salmeterol. The bronchodilator effect of both drugs lasts for approximately 12 hours, but formoterol has a faster onset of action. Studies report prolonged and rapid bronchodilation of formoterol with an onset of action at around 5 min, which is comparable with salbutamol and faster than salmeterol and which reaches peak bronchodilation within 1 hour. ${ }^{12-14}$ Because of formoterol's fast onset of action, it has a potential role for use as both a rescue and maintenance medication. ${ }^{15}$

Indicaterol is a novel, inhaled once-daily ultra-LABA ${ }^{16}$ for the treatment of COPD. It is likely that once-daily dosing of a LABA, which is indicarol in this case, will lead to enhancement of compliance with therapy and may have advantages leading to improved overall clinical outcomes in patients with COPD. Furthermore, in preclinical studies, the onset of action of indicaterol was similar to that of salbutamol and of formoterol, and was significantly faster than that of salmeterol. ${ }^{17}$

The numerous priorities of indicaterol related with 24-hour duration of bronchodilation, ${ }^{18}$ fast onset of action and a good overall safety and tolerability profile ${ }^{19}$ explain why this drug has earned an important place in the current management of Albanian COPD outpatients as the most used single LABA and the third most used inhaled $\beta_{2}$-agonist, after salbutamol and salmeterol plus fluticasone combination in 2012.

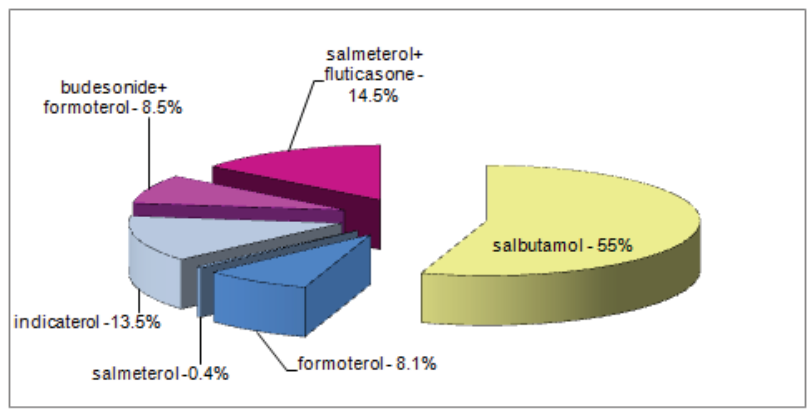

Figure 6. Utilization of inhaled $\beta_{2}$-agonists reimbursed for COPD treatment in Albania in 2012

LABAs had been preferred to be used in combination with inhaled corticosteroids (ICS). Inhaled ICS/LABA combinations represent $23 \%$ of inhaled $\beta_{2}$-agonist consumption reimbursed for treating COPD in primary care in 2012.

Guidelines recommend adding an ICS to long-acting bronchodilator therapy, for patients with with COPD stages III-IV and a history of repeated exacerbations. ${ }^{1}$ The physiological and clinical benefits of LABAs have been shown to be enhanced when administered in conjunction with ICS..$^{20,21}$ There is an excisting possibility that the observed benefit from combining these two classes of drugs might be due to a synergistic interaction with the resulting synergic effect being greater than the sum of responses achieved from each drug alone..22 Furthermore, single inhaler ICS/LABA is an appropriate choice when both agents are needed and may result in better treatment adherence. 23,24

Based on different pharmacological and clinical priorities, formoterol tends to be used as single and combined preparations almost equally in 2012. Salmeterol, as a LABA with more prolonged onset of action, is used nearly totally in combination with fluticasone propionate in one single inhaler during five years.

\section{Conclusion}

LABAs consumption is increased much more than the use of SABAs for Albanian insured outpatients with COPD during 2008-2012. LABAs are generally used with ICS combined in one single inhaler as these combinations have greater efficacy than either of their components used alone and are associated with an improved compliance to the therapy. Among plain LABAs, indicaterol has reached a significant use in 2012 being an ultra-LABA with 24-hour bronchodilation and associated with a better patient's adherence as an once-daily therapy. This trend of utilization of reimbursed inhaled $\beta_{2}$-agonists for the ambulatory treatment of COPD in Albania refered to the international guidelines which recommend SABAs for as-needed symptom relief and LABAs as long-term maintenance therapies. At last, it can be concluded that inhaled $\beta_{2}$-agonists added up recently in the Albanian list of reimbursed drugs and which represent advanced pharmacological therapies have made possible a contemporary management of COPD outpatients. 


\section{References}

Global Initiative for Chronic Obstructive Lung Disease (GOLD). Global Strategy for Diagnosis, Management, and Prevention of Chronic Obstructive Pulmonary Disease. (Revised 2011). Available at: http://www.goldcopd.org Accessed online May 05, 2013

O'Donnell DE, Aaron S, Bourbeau J, et al ; Canadian Thoracic Society. Canadian Thoracic Society recommendations for management of chronic obstructive pulmonary disease-2003. Can Respir J 2003; 10 (Suppl A): 11A-65A.

Introduction to drug utilization research / WHO International Working Group for Drug Statistics Methodology, WHO Collaborating Centre for Drug Statistics Methodology, WHO Collaborating Centre for Drug Utilization Research and Clinical Pharmacological Services. WHO 2003.

WHO Collaborating Centre for Drug Statistics Methodology, Guidelines for ATC classification and DDD assignment 2012. Oslo, 2011.website: www.whocc.no

American Thoracic Society/European Respiratory Society Task Force. Standards for the Diagnosis and Management of Patients with COPD. Version 1.2 New York: American Thoracic Society; 2004.

NICE clinical guidelines. Chronic Obstructive Pulmonary Disease: Management of Chronic Obstructive Pulmonary Disease in Adults in Primary and Secondary Care. Issued: June 2010 http://www.nice.org.uk/Guidance/CG101

Hanania NA. The impact of inhaled corticosteroid and long-acting beta-agonist combination therapy on outcomes in COPD. Pulm Pharmacol Ther 2008; 21:540-50. http://dx.doi.org/10.1016/j.pupt.2007.12.004

Kiri VA, Bettoncelli G, Testi R, Viegi G. Inhaled corticosteroids are more effective in COPD patients when used with LABA than with SABA. Respir Med. 2005 Sep;99(9):1115-24. Epub 2005 Mar 21.

Balint $\mathrm{B}$, Watz $\mathrm{H}$, Amos $\mathrm{C}$, et al. Onset of action of indicaterol in patients with copd: comparison with salbutamol and salmeterolfluticasone. Inter J COPD 2010; 5: 311-318

Wang J, Nie B, Xiong W, et al. Effect of long-acting B-agonists on the frequency of COPD exacerbations: a meta-analysis. J Clin Pharm Ther 2012; 37: 204-211.

Jones PW, Barnes N, Vogelmeier C, et al. Efficacy of indicaterol in the treatment of patients with COPD. Prim Care Respir J 2011; 20:380-388.

Benhamou D, Cuvelier A, Mur JF et al. Rapid onset of bronchodilation in COPD: a placebo-controlled study comparing formoterol (Foradil Aerolizer) with salbutamol (Ventodisk). Respir Med 2001; 95: 817-821.

Kottakis J, Cioppa GD, Creemers J et al. Faster onset of bronchodilation with formoterol than with salmeterol in patients with stable, moderate to severe COPD: results of a randomized, double-blind clinical study. Can Respir J 2002; 9:107-115.

Condemi JJ. Comparison of the efficacy of formoterol and salmeterol in patients with reversible obstructive airway disease: a multicenter, randomized, open-label trial. Clin Ther 2001; 23:1529-41.

Campbell M, Eliraz A, Johansson G. et al. Formoterol for maintenance and as-needed treatment of chronic obstructive pulmonary disease. Respir Med 2005;99:1511-1520.

Cazzola M, Matera MG, Lotvall J. Ultra long-acting beta2-agonists in development for asthma and chronic obstructive pulmonary disease. Expert Opin Investig Drugs. 2005; 14: 775-783.

Naline E, Trifilieff A, Fairhurst RA, Advenier C, Molimard M. Effect of indicaterol, a novel long-acting beta2-agonist, on isolated human bronchi. Eur Respir J. 2007;29:575-581.

Bauwens $\mathrm{O}$, Ninane $\mathrm{V}$, van de Maele B, et al. 24-hour bronchodilator efficacy of single doses of indicaterol in subjects with COPD: Comparison with placebo and formoterol. Curr Med Res Opin. 2009; 25:463-470

Beier J, Chanez P, Martinot JB, et al. Safety, tolerability and efficacy of indicaterol, a novel once-daily beta 2-agonist, in patients with COPD:A 28-day randomized, placebo controlled clinical trial. Pulm Pharmacol Ther. 2007;20:740-749

Cazzola M, Dahl R. Inhaled combination therapy with long-acting $\beta 2$-agonists and corticosteroids in stable COPD Chest 2004; 126;220237

Barnes NC, Qiu YS, Pavord ID. SC030005 Study Group. et al Antiinflammatory effects of salmeterol/fluticasone propionate in chronic obstructive lung disease. Am J Respir Crit Care Med 2006; 173: 736-743

Cazzola M and Dahl R. Inhaled combination therapy with long-acting $\beta 2$-agonists and corticosteroids in stable copd. Chest 2004; 126: 220-237

Cazzola M, Hanania NA. The role of combination therapy with corticosteroids and long-acting beta2-agonists in the prevention of exacerbations in COPD. Int J COPD 2006; 1:345-354

Blanchette CM, Akazawa M, Dalal A, Simoni-Wastila L. Risk of hospitalizations/emergency department visits ad treatment costs associated with initial maintenance therapy using fluticasone propionate $500 \mathrm{mcg} / \mathrm{salmeterol} 50 \mathrm{mcg}$ compared with ipratropium for chronic obstructive pulmonary disease in older adults. AM J Geriatr Pharmacother 2008; 6: $138-46$. http://dx.doi.org/10.1016/j.amjopharm.2008.08.005 